\title{
PROSPECTS FOR THE DEVELOPMENT OF CLUSTER FORMS OF ENTREPRENEURSHIP IN EUROREGIONS
}

\author{
Oleksandr Laiko', Sergey Kovalenko'², Oleksandr Bilousov ${ }^{3}$
}

\begin{abstract}
The aim of the proposed research consists in outlining prospects of cluster mechanism application and verification of the cluster strategy in view of innovative development of cross-border regions against the background on strengthening integration processes. The work is dedicated to research of theoretical, methodical and applicable basis of strategic management of development of international integration associations as network-like structures of intra-branch and inter-branch cooperation on their mesolevel. The research method is based on mesoeconomic synthesis of development concepts in industrial and innovative clusters and international integration associations. To the authors' opinion, it enables to work out both mechanism and scientific understanding of development trends in modern integration systems. The scientific hypothesis of the proposed work suggests that the cluster approach is the most efficient mechanism of development of international economic cooperation under modern conditions and, finally, is a mesolevel of competitive international integration systems and necessary pre-condition of qualitative progress of integration of Ukraine into the EU. The authors propose to develop integration processes of mesolevel within the framework of unified economic space basing upon clustering. Concept, structure and life cycle of net forms of self-organization of a cross-border economic space in conditions of developing a postmodern economy are considered. Conclusion is drawn to state that the cross-border clusters concept construes an approach adequate to modern challenges to stimulate economic development of peripheral regions with inherent features and advantages taking into account comprehensive dynamic competition and coordination of problems of meso- and macrolevels with conditions accompanying operation and activity of particular business entities. Under such circumstances, cluster policy consists in creating conditions for formation and development of cross-border clusters, but, under no circumstances, in artificial generation of such clusters. Theoretical positions and methodological approaches to the formation of industrial clusters within European regions are systematized. The essence of cross-border and internal relationships of the cluster as a factor in increasing competitiveness in the increasingly Euroregion integration processes and the need to enhance the role of peripheral regions within the framework of crossborder cooperation. The strategic priorities for spatial development of new forms of cross-border cooperation in the context of regional policy of the EU are outlined.
\end{abstract}

Key words: quasi-integration, mesocompetitiveness, cluster, cross-border cluster system.

JEL Classification: O31, M16, F23

\section{Introduction}

The ability to adapt promptly to international competition becomes the most important condition of sustainable development. Competition is occupying a priority position in placing aims for management of enterprises.
Development of "newer" economy occurs as a result of transfer from centralized management of economic space to pluralism and, further, from vertical hierarchy to horizontal networks. This process is defined among Western scientists as "quasi-integration". Such conditions demand search for newer sources of economic growth,

\footnotetext{
Corresponding author:

${ }^{1}$ Institute of Market Problems and Economic-Ecological Research

of the National Academy of Sciences of Ukraine, Ukraine.

E-mail: alexlayko@gmail.com

ORCID: https://orcid.org/0000-0001-7082-0862

${ }^{2}$ Danube Institute of National University “Odessa Maritime Academy”, Ukraine.

E-mail: kovalenko@dinuoma.com.ua

ORCID: https://orcid.org/0000-0001-7430-9412

${ }^{3}$ Odessa National Polytechnic University, Ukraine.

E-mail: A.biliusoff@gmail.com

ORCID: https://orcid.org/0000-0003-2535-5505
} 
formation of flexible business structures enabling to react promptly to changes in economic situation and to generate competitive advantages of high level, as demanded by increased degree of virtualization in economy.

Steady competitiveness growth is identified as a critical factor enabling to achieve strategic aims, improve political and economic role of Eastern European states in global community. The need for development newer theoretical approaches to problems of forming and improving competitiveness on mesolevel is longstanding and requires studying worldwide experience in this field (Andersson T. Schwaag-Serger, Sorvik, Hansson, 2004). Specific features of this stage place new objectives in researching problems of competitiveness improvement at the level of enterprises as essential participants of competitive relations. First of all, the matter concerns revealing of factors and conditions facilitating to creation of competitive advantages, choice of adequate mechanisms and instruments enabling to improve competitiveness of enterprises.

Urgency of Research is caused by severe demand to improve competitiveness of native industry at mesolevel by means of establishing clusters in competitive branches and lack of scientifically validated organizational and economic approaches, methodological tools and strategies for implementation of the specified demand under prevailing economic circumstances. Newer conceptual approach should be developed enabling to improve mesolevel of competitiveness of industrial enterprises on the basis of boosted clustering processes in branch composition and space structure of industry in general.

Current situation requires decisive actions not only to improve competitiveness of native manufacturing, reviving innovative activeness, but also to achieve a breakthrough in this area. This problem may be solved by means of creating competitive clusters in native industry. Solution of the mentioned problem is capable to provide construction of structures to improve competition of entire economy by means of concentration upon creation and development of newer hi-tech manufactures based on the most recent scientific and technical discoveries with high share of knowledge factor in production. In this view, a demand rises to develop organizational, economic and methodological recommendations aimed to improve competitiveness of native industry within mesolevel basing on cluster approach.

Aim of the proposed research consists in outlining prospects of cluster mechanism application and verification of the cluster strategy in view of innovative development of cross-border regions against the background on strengthening integration processes and development of cross-border cooperation. In this context the authors have chosen to reveal preconditions and key factors of generation of cross-border cluster systems and identification of the part they may play in innovative capabilities of Euroregions.

\section{An overview of the relevant publications}

Strong resemblance between clusters, industrial areas and complicated adaptive (capable to self-organization) systems are marked by a number of researchers. As M. Porter writes, "Cluster is a system of interconnected corporations and institutions which in total exceeds a mere sum of its components", thus displaying systemic effects and self-organization basis of clusters (Porter, 1998).

Michael Porter in his work "The Competitive Advantage of Nations" draws a remarkable conclusion, as follows, "...developing an investment policy transition economy should strive to develop mutually dependent industrial cluster involving basic and auxiliary branches of industry" (Porter, 1990). An approach to estimate a regional competitiveness may be formulated basing upon a national competitiveness concept proposed by M. Porter.

Prof. T. Brenner from Max Planck Institute of Economic suggests that "... cluster is reviewed as a result of evolutionary processes forming specific conditions and motivating forces in a certain particular area in a certain particular time leading to a phenomenon called in literature as a cluster, industrial area, innovative environment, etc." (Brenner, 2001). Clusters are directly associated with systems capable to self-organization in another work by Prof. T. Brenner, “... local system is considered as a set of corporations operating in one or more branches of economy deriving mutual advantages from their proximity to each other and local accessible conditions and resources. Cyclic stimulating mechanisms are inherent with such or similar systems capable, together with favorable local conditions, to maintain high level of employment within the corporations, which, in their turn, support local favorable conditions. It means observing aspects with positive influence upon each other and thus bringing their state to a new, more advanced level. These are the features of a system capable to self-organization" (Brenner, 2000).

Important contribution in development of theory of economic space organization has been made by economists representing institutionalism trend (O. Williamson, R. Coase, W. Nordhaus, F. Hayek). In their works they drew utmost attention to lack of information, affecting mutually profitable activities, differences in obvious and "hidden" knowledge concentrated on studying influence of transactions expenditures on advantage of various forms of organization (Williamson, 1985). Their works displayed their being aware of existence and importance of net clusters phenomenon, including researches in growth poles and structures with direct links and feedbacks, reviews of agglomerations' economy, economic geography, urbanized and peripheral economy, national innovation systems, regional science, industrial areas and social structures (Coase, 1994). 
Works by M. Kastels and M. Himanen showed on the basis of Oulu technopark that it is linked with foreign corporations to greater extent, than with its own business entities. However, the technopark shows economic progress only where and when it is joined with significant innovative clusters. Technoparks activities' efficiency analysis influenced transformation of Finnish national policy in economic development from programs based on national priorities towards supporting private and public entities involved into regional development (corporations, local authorities, public initiatives) in their business activities (Nordhaus William, 1969).

"Possible self-organization, i.e. spontaneous emergence of order from chaos is experimentally proved and theoretically grounded for the most various opentype unbalanced systems". In general, a self-organizing system is defined as a "complicated dynamical system capable to preserve or to improve its organization in altering external or internal conditions of its functioning and development considering the past experience" (Cluster policy in Europe, 2008).

\section{Research methods}

The research focuses on solving a fundamental problem of competitiveness improvement for Ukrainian industrial enterprises on mesolevels basing on cluster approach to validation of sources of competitive advantages and mechanism of their application. In view of growing involvement of Ukraine into global economic processes, formation of mesocompetitive clusters becomes particularly urgent for our state. Competitiveness in view of new production mode is determined by innovations' intensity rate and capability to continuous renewal. Thus, there is a necessity to establish a methodology of cross-border cluster systems' development as a mesolevel of international economic integration. Methodology in this research means a set of organization and development principles and methods of cross-border cluster systems' generation as elements linking together integrating national economic systems. Complex of problems reviewed in this work is of multisubjects nature and encompasses a lot of theoretical approaches and concepts. However, in general it may be subdivided into a few essential blocks:

- problems of international economic integration in theoretical and practical aspects in the post-crisis period;

- development of inter-institutional networks in view of industrial innovative clusters;

- turning to mesoeconomy as a uniting link between two blocks.

However, even in view of deep study of theoretical approaches to processes of international economic integration, in general, and to development of clusters, in particular, on the level of individual enterprises, branches and regions, there is no uniform concept of international economic integration applying methodology of development of international industrial innovative clusters. Such a problem statement may be described as mesoeconomic synthesis of industrial innovative clusters' and international integration associations' development concepts, and, to our opinion, enables to develop mechanism and scientific understanding of development of modern integration systems.

The scientific hypothesis of the proposed work represents an allowance that the cluster approach is the most efficient mechanism of development of international economic cooperation under modern conditions and, finally, is a mesolevel of competitive international integration systems and necessary precondition of qualitative progress of integration of Ukraine into the European economic space.

\section{Results of the research}

Cluster policy is the most efficient instrument of competitiveness improvement of a national economy under prevailing conditions. Cluster policy started to be applied in some European states since 1980s. It should be noted, that "Clustering Manifest in EU Member States" (Vienna Cluster Manifesto) was approved in 2006 (2012) and "European Cluster Memorandum" was approved in 2008. Substantial number of clusters already operate in EU. For example, there are 206 clusters in Italy, 168 in the UK, 96 in France, 34 in Denmark, 32 in Germany, 20 in Netherlands and 9 in Finland. Global experience shows that during recent times the process of clusters' formation runs actively in the USA (380) and in India (106).

"Cluster policy" should be understood as a "system of governmental and social clusters and cluster initiatives' support measures and mechanisms facilitating to improve competitiveness of enterprises and regions included into the cluster, development of institutions facilitating the clusters' formation and innovations' implementation". There are a sufficient number of positive examples of cross-border inter-corporate cooperation on mesolevels including industrial innovative clusters. However, experience of corporations and states in this aspect is insufficiently studied and common features, obstructions and stimulations to develop such a cooperation system remain unrevealed. Decrease of a part previously played by territorial component of manufacturer's location with developing IT and economic space tendency to self-organization leads to formation of virtual inter-corporate networks and provides an opportunity to create cross-border cluster systems capable to evolve rapidly under prevailing circumstances. Thus, cluster approach becomes more advanced and enables to involve a great quantity of corporation and states worldwide into data exchange. 
To date, the uniform concept of the European economic integration based on methodology of development of international industrial and innovative clusters is not formulated.

Economic cluster is a result of self-organization of subjects of economic activities applying efforts to achieve aims of their own and acting within the framework of their individual interests with their strategic interests being related together and are implemented more efficiently by means of cooperation within the structure of economic cluster. Economic cluster, from this point of view, provide its participants an advantage identified as agglomeration economies. The effect of the agglomeration economies is generated by means of following factors:

1) reduction of transactional and manufacturing costs of various kinds due to savings on scales and logistics;

2) concentration of business entities at certain territory increasing the innovative index of production (with ideas circulation partly being an essential factor of the latter);

3) knowledge spreading migration;

4) emergence of technological partnership, where a few cooperating corporations (even competing with each other) coordinate their research and development activities, products design, basic technologies, which are further implemented into specific final products by each enterprise (Enright, 2000).

\section{Neo-factors of enterprises' competitiveness growth in mesolevels generated by acceleration of clustering process}

1. Innovations. Worldwide experience showed, that clustering of cross-border economy causes and decisively influences processes of competitiveness improvement and boosting innovative activities. IT forms a newer economic phenomenon, which enables to counteract the pressure of global competition and respond adequately to requirements of national and regional development. Priority of essential factors of deployment changes substantially in modern postindustrial paradigm affecting the functions of peripheral territory. It transforms from the location of material factors of production (resources) as a physical basis into spatial environment for development of human capital, innovations and Euroregional self-development.

2. Institutional transplantation. Transplantation is defined as a process of transfer of institutions, which developed into another institutional environment.

Newer postmodern reality lies in association of post-industrial manufacturing with network structure of economic space which provides for institutional transplantation by means of self-organization of hybrid network clusters at both sides of border which becomes a concentration factor and free circulation of monetary funds in Euroregions.
With newer manufacturing mode, the competitiveness is defined by innovations implementation rates and capability to continuous renewal. Thus, the postindustrial economy evolved into a system of cooperating institutions, forming a new cluster postmodern paradigm in cross-border dimension, requiring virtual resources for development, such as information, innovations, communications, knowledge. This process started in all states practically simultaneously (including Ukraine). However, it may be noticed, that states of Central and Eastern Europe are rather more advanced in this aspect. In comparison with Ukraine, these states achieved the crucial aim of the EU integration. Here a substantial part was played by cross-border cooperation institute as an experimental array for testing and adapting the European laws, instruments improving roles played by regions, adaptation of financial support mechanisms.

This strategy means a possibility to apply an institution "from the past" of donating state at any stage of its development. It is supposed that spontaneous evolving of a transplanted institution will (directly or implicitly) facilitate to generation of format meeting the requirements of the recipient state. The "growth" allows simultaneous transplantation of multiple versions of the institution and their coexistence (competition) with similar institutions of the recipient and, to the authors' opinion, possible corrections to be introduced into the process of transplantation.

3. Synergistic effect. Cluster framework generates an additional economic effect, which improves competitive advantages of the region. Enterprises within a cluster earn an additional synergistic effect due to shared usage of resources (technologies and expenditures strategy), market infrastructure (joint sales), and spheres of activities (planning and management synergy). Meaning of synergy strategy consists in its possible usability to obtain higher efficiency of manufacturing with relations between enterprises involved into cluster that in situation when they are controlled separately. Synergistic effect is an activity efficiency increase as a result of association, integration, merging of individual parts into a single system due to so-called positive system effect (emergence effect), with effect achieved by cooperation of participants in integrated system exceeds total summarized effect of activities of each individual (autonomous) participant. I. Ansoff, a famous economist and theoretician in strategic management, proposed a term "synergism" describing it as a difference between total effect of common usage of resources and a sum of individual effects from using same resources separately. Synergistic effects is formed as a result of a process of deriving direct economic, system and strategic effects united into hierarchy system and consists in such an increase of operational indexes, which exceed the total increase of indexes of integrated systems achieved by means of traditional scenario of development. 
4. Transfer of technologies and knowledge. It is regarded as one of the aspects of innovative process. The latter means a transformation of scientific knowledge into innovation. It may be represented as a sequence of events, in the course of which the innovation passes a way from an idea to a particular product, technology, or service and spreads during practical application. Consequently, the innovative process efficiency, e.g. hi-tech production, is connected with transfer of newer knowledge from one group of involved parties to others (developers, technology holders, intermediate parties, authorities and administrative bodies, investors, potential purchasers).

Economic development of any states requires increase of transfer rates of unique and advanced technologies, attraction of funds for development of innovative activities. Enterprises' clustering facilitates to development of certain types of technologies transfer, such as:

5. Quasi-integration. "Integration/Disintegration" dichotomy applied in modern theory of economics is supplemented with another category known as "quasi-integration". Another dichotomy, "Corporation/ Market" is expanded with the "Hybrid" category. Distinguishing feature of a cluster as a version of quasiintegration is its geographical localization, which reflects concentration of mutually related corporations, specialized suppliers and servicing organizations within a limited territory where they compete and carry on joint activities at the same time. Clusters so far remain such a theoretical construction which does not possess sensible images and clear externalities. However, these quasi-integrating forms will become a main moving force of innovative development in long-term future (Kovalenko, 2019).

6. Cooperation. Development of cross-border cooperation leads to appearance of cross-border market, which may be defined as a system of cooperation of international business entities at regional level, where economic exchange and joint usage of material, financial and human resources takes place within a framework of a common cross-border region. In this case, the presence of a border effect is mitigated by means of creation of cross-border network structures in economic space organization. They possess a greater potential in view of demand for efficient application of homogenous manufacturing factors, such as knowledge capital, information, innovative technologies.

7. Self-organization. Rapid IT development led to emergence of network society. Sophistication of economic space accompanied by bifurcations leads inevitably to its self-organization. Due to IT network, society becomes capable to establish contacts, generate links, mitigate effects of borders, conformities and cause multiple newer opportunities in the form of bifurcations, such as computerized trading, virtual societies, virtual enterprises, creation of cybernetic cities. Network economy is super-transparent and super-prompt. The most important is that it creates favorable conditions for importing efficient institutions by means of working out new form of organization for postmodern economic space.

8. Branding. It is a consistent and gradual creation of a trademark popular among the targeted audience and implementing an appropriate approach into the corporation policy. Branding is a set of marketing tools. The process of brand management consists in development of a trademark for a production item, positioning and promotion at the market, care of reputation and continuous monitoring for individual trademark compliance to demands of the market. It is possible to state that branding, in its present interpretation, means a systematic, scrupulous process providing for planning and implementation of complex measures to create a trademark, planning approaches to transform trademark into brand to form desirable associative impressions and gain expected advantages among customers and consumers (Figure 1).

On the other side, the increase of competition intensity stimulates counteragents to more active search for innovations. Cooperation between the parties depends on competition (back feed in the most primitive version). Cooperative interactions simulate the most preferable technologies and ways to do business effecting innovative and technological components. Description of cooperation process takes into note a proximity and mutual influence of the parties located in innovative and technological area. Clusters may be determined as groups of independent corporations and associated organizations located within the same geographical region, which cooperate and compete, specialize in various areas, linked with common skills and technologies and supplement each other, which, finally and in total, enables to obtain synergetic and network effects, diffusion of knowledge and skills. Cluster frameworks generate additional economic effect and improve competitive advantages. Enterprises involved into cluster gain an additional synergistic effect due to common usage of resources (technologies and expenditures strategy), market infrastructure (joint sales) and spheres of activities (planning and management synergy). Synergy strategy part consists in the fact that it enables to gain higher manufacturing efficiency with cluster participants' enterprises cooperating with each other than in the case when they are run separately. Synergistic effect is an efficiency increase as a result of establishing an association, integration, merging individual parts into united system by means of so-called positive system effect (emergence effect), where effect from cooperation of participants in integrated system exceeds total summarized effect from activities of each particular participant who act autonomously. 


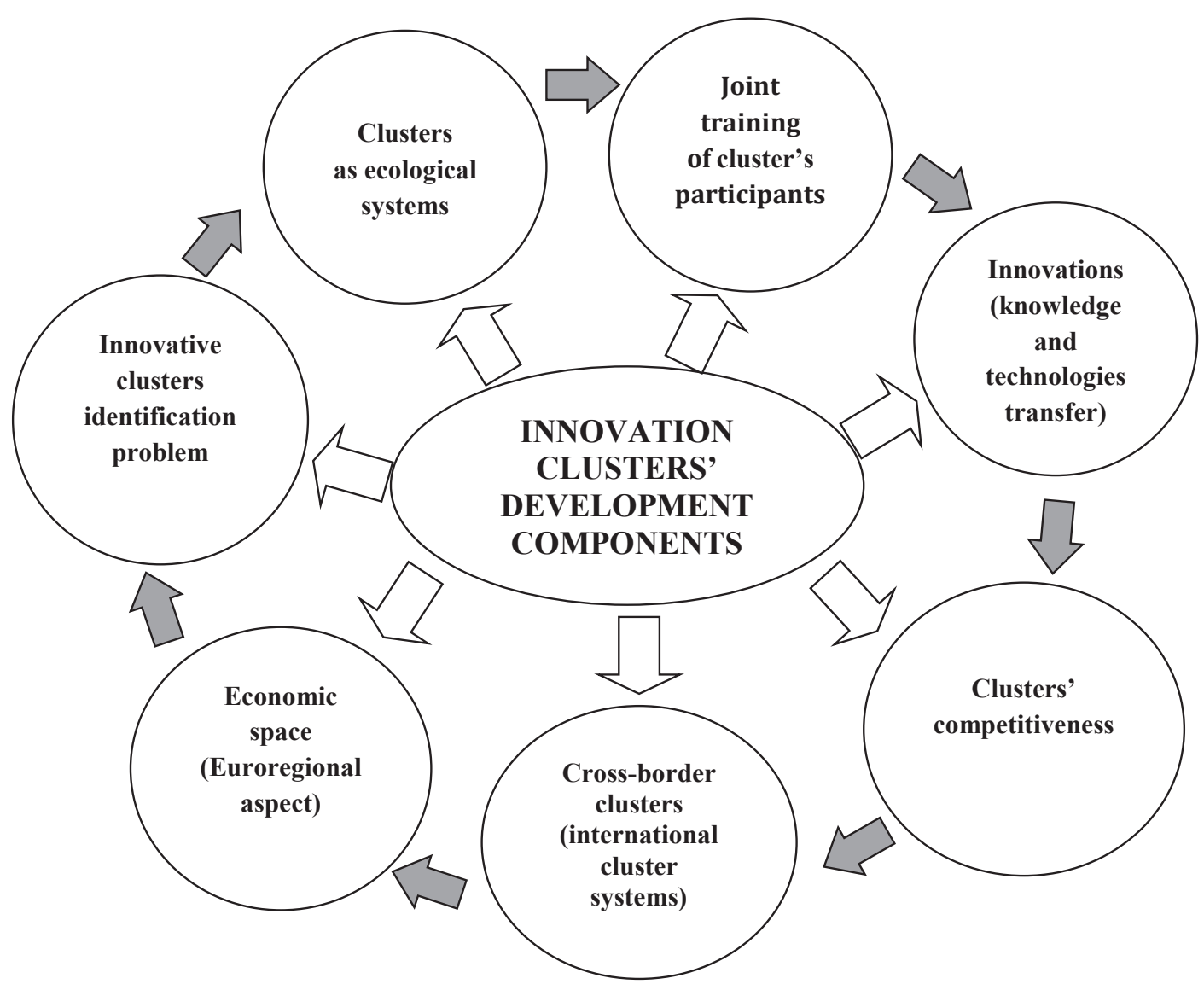

Figure 1. Trends in innovative clusters' theory development

Source: the authors' own work

\section{Essential advantages of clusters}

As a result of competitiveness research problems, M. Porter found three essential advantages of clusters:

Firstly, they increase productivity providing an access to specialized labor and resources and making data, institutions and common public benefits easier to access.

Secondly, clusters encourage higher rate of generating newer business formations transforming employees of existing corporations into brand new businessmen.

Thirdly, they improve corporations' capability to implement innovations due to more rapid diffusion of technological knowledge. Unique feature of clusters to boost innovations' diffusion enables to define them as innovatively active economic agglomeration of an area of innovative activeness. Any cluster represents a network structure with ideology of competitive cooperation (or non-competition) where motivations to progress generated by competition among the network participants are combined with improvement of cooperation in mutually beneficial directions (Porter, 1998). Network model of national economic space organization becomes more prospective under prevailing conditions. This model was placed into foundation of economic organization in those regions, which appeared to be the most successful in the system of global exchange of goods, finances, labor, technologies and data. They represent a network of autonomous and yet mutually substitutable enterprises.

Mesoeconomy is supposed to play a part of connecting "bridge" between microeconomy and macroeconomy being, however, an under-estimated component of economics as a science, especially from the point of view of modern international economic relations. Briefly, mesoeconomy may be defined as a system of inter-branch contacts consisting of certain types of networks and chains. Mesolevel of international economic integration is an organizational structure of intra-branch and inter-branches cooperation in the form of international cluster systems involving macroand micro- integration levels of national economies. Cross-border clusters are formed in regions adjacent to national borders in two or more states "beyond" their administrative borders. They encompass adjacent territories of neighboring states with institutions and corporations located at both sides of borders. Therefore, cross-border clusters may be defined as groups of independent corporations and associated institutions 
which are geographically concentrated in cross-border region, compete and cooperate, specialize in various branches, related to common technologies and skills and mutually supplement each other, which, finally, enables to obtain synergetic and network effects, diffusion of knowledge and skills (Figure 2, Figure 3).
At the same time, virtualization processes of intercorporate cooperation gradually started accompanied by appropriate virtualization of clusters (Kovalenko, 2017).

In general, logical aspect of concept synthesis of international cluster systems as a mesolevel of

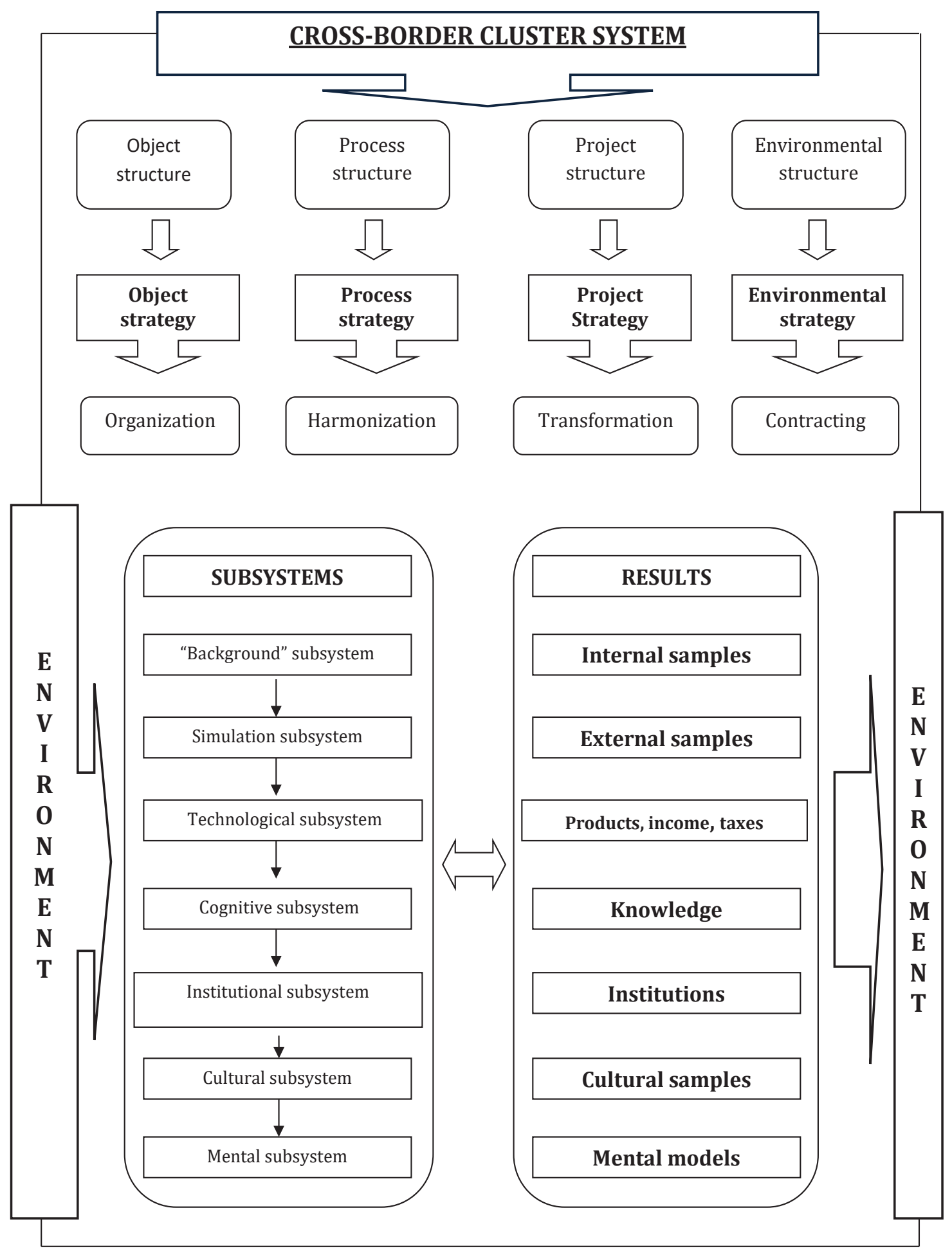

Figure 2. Structure of subsystems and results in cross border cluster system

Source: compiled by the authors 


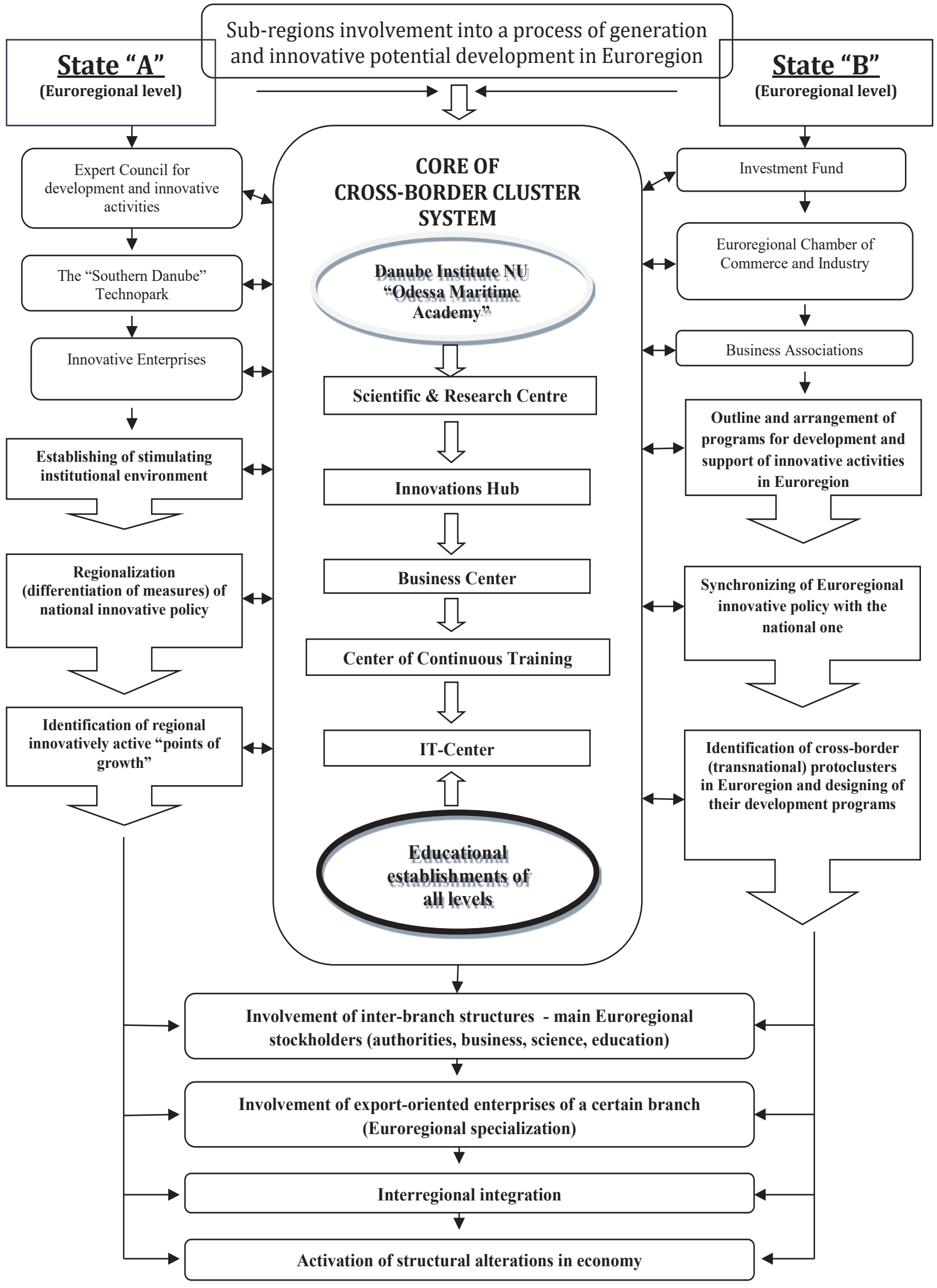

Figure 3. Model of Euroregional innovation potential based on cross-border clustering

Source: compiled by the authors 
international economic integration bases of the following criteria:

- necessity to improve efficiency of regional integrating structures in terms of accelerating economic and innovative cycles;

- character of international economic integration mesolevel (regions, institutions, inter-corporate networks); - international cluster system representing mesoeconomic approach most completely under prevailing conditions;

- international clusters as business ecosystems, evolutionary network approach to development of international economic integration.

Cross-border cluster systems are convenient since they generate certain effects of synergy and are efficient being low cost at the same time. Main sources of synergy in clusters are knowledge exchange, mutually accessible qualified labor for participants or possibility to use jointly general social benefits. Cluster in such a context represent signal characteristics of "real" economy. Cluster strategies and cluster thinking possess a sufficient potential to boost regional economic growth and produce a favorable influence upon economic restructuring. However, the most crucial factor in this context lies in a provision that clusters are a paradigm to great extent. So, another reason of addressing to cluster concept lies in the fact that clusters, further to a pure practical aspect, provide a powerful paradigm to understand principles of economic life and economic policy (Hayek, 1945).

The Cross-Border Cluster Systems, (CCS), are proposed for review as objects of strategic planning. They are defined as territorially localized social and economic system established by a group of independent economic entities at both sides of the border involving also administrative bodies of states, participants of the Euroregion and public bodies. They stably cooperate with each other in forms of data exchange, services exchange, personnel and funds exchange and provide higher efficiency in comparison with other objects not organized systematically (Kovalenko Sergey, 2020). Cluster formation review should be carried on not only basing on social and economic system criteria, but also referring to estimated competitiveness increase of the clusters being under formation. In this view, both External (generated on levels of national economy, regional economy, or branch) and Internal Cluster Effects, caused by synergistic effects produced by their participants should be considered.

Cluster manufacturing structure synthesizes synergy effect based on universal standardizing of production. It should be emphasized that it is cluster approach which nowadays became one of the main trends of national policy in advanced and developing states aimed on improvement of national competitiveness.

The proposed cluster approach to improve competitiveness of industrial enterprises represents a special combination of territorial and inter-branch management principles enabling to stimulate integration processes on mesolevel of economy (Figure 3).

Cluster approach is, certainly, necessary, since it focuses, in essence, upon solution of essential problems of national economy.

Firstly, as the cluster approach is implemented, the main aims are development of competitive market, supporting competition as a driving force of corporations' competitiveness. It should be noted that economy of Ukraine features a high degree of monopolization of regional and local markets which negatively affects competitiveness of economy in general. Here governmental initiatives in cluster policy are aimed, first of all, towards providing support to stronger and more creative corporation and creating favorable environment for weaker and obsolete corporations to improve their competitiveness.

Secondly, formation of clusters pays the greatest attention to microeconomy - studying local markets and corporations on the basis of built up manufacturing factors (skilled personnel, accessible infrastructure, etc.) and not inherent ones (natural resources, etc.). Microeconomic approach to clusters' formation enables to take into account local specifics and work out efficient programs to boost development and improve competitiveness of corporations.

Thirdly, cluster approach implementation is based on organization of cooperation between governmental administration bodies and those of local administration, business entities and scientific and educational establishments to coordinate efforts to improve innovative nature of manufacturing and services facilitating mutual improvement of operational efficiency.

Fourthly, cluster approach is aimed to stimulate development and improve innovative potential for minor and medium business, which occupies weaker positions in native economy in comparison with advanced states. Mainly minor and medium business entities form clusters and cluster initiatives - the essential objects in cluster approach implementation.

\section{Conclusions}

In general, methodology approach to industrial enterprises competitiveness improvement may be formulated in the manner, as follows,

- Hierarchical pattern, the implementation of system approach as a cornerstone principle of scientific cognition supposes actions to be developed for all three levels - microeconomic, mesoeconomic and macroeconomic - basing upon competitiveness category. In this case the higher level of competition field creates conditions for actions for lower level efficiency of which, in their turn, construes a way to achieve competitiveness aims put on a higher level. 
Vertical unity in achieving competitiveness determines logics of development of management tools.

- Forming of competitive advantages for Ukrainian enterprises should be based, firstly, on applying mechanisms of mesoeconomy instead of microeconomy mechanisms. Numerous important processes occur on branch, regional and quasi-corporative levels without which competitive advantages cannot be achieved by means of reconstruction and improvement of value generation chains. These processes are currently the least involved in the industry.

1. Industrial business network become the essential objects of economic management in post-industrial economic system. They take a form of network cluster experiencing the impact of globalization and internationalization processes. European integration opens newer opportunities for Ukraine and its regions. At the same time, integration of Ukraine into the European economic space demands to develop own competitiveness strategy concept, formation of appropriate social ideology for competitiveness of each of cross-border regions.

2. Globalization of markets and competitiveness increase led to growing popularity of newer manufacturing innovative model with all the participants striving to unite into clusters. Cluster development as a factor improving regional competitiveness is a typical feature of modern innovative economy. Global practice showed that clustering of cross-border economy produces a decisive effect on competitiveness improvement processes and boosting of innovative activities. It represents a newer economic phenomenon enabling to counteract the pressure of global competition and respond duly to demands of national and regional development.

3. Development of international competition led to development of newer theories of competitive advantages formation. Competitiveness development bases on determinants of national "golden section" and operates in the form of competing clusters of national economy.

4. Newer postmodern reality consists in combination of postindustrial manufacturing with network structure of economic space. It supposes institutions transplantation by means of self-organization of hybrid network clusters at both sides of the border, which becomes a factor of consolidation and free circulation of monetary resources in Euroregions.

5. To date, development and implementation of Euroregional cross-border development strategy referring to European experience of cross-border strategies gains an utmost urgency. Its object is a stable and steady social and economic development of Euroregional system in conjunction of its human, natural and manufacturing potentials on the basis of network clusters. Development of efficiently operating clusters is a substantial step on the way towards development of Euroregional economy, improvement of competitiveness of production manufactured within their territories. Corporations, especially minor, may be able to enter global markets with their production only by means of cooperation and consolidation of efforts. This principle lies in the foundation of entire competitiveness system of states, regions and territories in global economy.

\section{Acknowledgements}

This publication was prepared within the framework of the scientific project "Organizational and economic mechanisms of increasing entrepreneurial activity in Ukraine" at the expense of the budget program "Support of priority areas of scientific research development" (KPKVK 6541230).

\section{References:}

Andersson, T., Schwaag-Serger, S., Sorvik, J., \& Hansson, E. W. (2004). The Cluster Policies Whitebook. Malmo, Sweden: International organization for knowledge economy and enterprise development.

Brenner, T. (2001). Simulating the evolution of localised industrial clusters - an identification of the basic mechanism. Journal of Artificial Societies and Social Simulation, vol. 4(3). Available at: http://jass.soc.surrey.ac.uk/4/3/4.html

Brenner, T. (2000). The Evolution of Localised Industrial Clusters: Identifying the Processes of Self-Organisation // Papers on Economics \& Evolution, Jena.: Max-Planck-Institute. Available at: http://www.econ.mpg.de/ files/2003/staff/brenner/selfaug.pdf

Coase, R. H. (1994). Nature of the Firm [Text] / Lessons business organization. St. Petersburg: Lenizdat.

Cluster policy in Europe / A brief summary of cluster policies in 31 European countries (2008). Europe Innovation Cluster Mapping Project. Oxford Research AS, January.

Enright, M. J. (2000). Survey on the Characterization of Regional Clusters: Initial Results: [working paper]. University of Hong Kong, Institute of Economic Policy and Business Strategy: Competitiveness Program.

Hayek, F. A. (1945). The Use of Knowledge in Society. American Economic Review, vol. 35(4), pp. 519-530.

Kovalenko, S. (2020). Cross-border cluster system as an object of strategic planning. Cluster model of innovative development of the national economy: Integration and Infrastructure Aspects: Collective monograph $/$ under the editorship of professor Svitlana Smerichevska. Poznan, Poland, WSPIA. 
Kovalenko, S. I. (2017). The mesolevel of self- organization of cross-border economic space on the basis of network clusters. National Economic Development and Modernization: experience of Poland and prospects for Ukraine: Collective monograph. Edited by A. Pawlik. Vol. 2. Poland: State University of Jan Kochanowski, Baltija Publishing. Kovalenko, S. I. (2019). Strategic management of the development of cross-boundary cluster systems: Euroregional dimension. Monograph. Odessa, National University "Odessa Maritime Academy", LLC "Courier Publishing House".

Nordhaus William, D. (1969). Invention, Growth and Welfare: A Theoretical Treatment of Technological Change. M.I.T. Press.

Porter, M. E. (1998). Clusters and competition: new agendas for companies, governments, and institutions. On Competition. Boston, MA: Harvard Business School Press.

Porter, M. (1990). The Competitive Advantage of Nations. London: Macmillan.

Williamson, O. (1985). The Economic Institutions of Capitalism. New York: Free Press. 